Review Article

\title{
Socioeconomic Status and Mental Health among Low-income Employees: A Systematic Literature Review
}

\author{
Errna Nadhirah Kamalulil and Siti Aisyah Panatik* \\ School of Human Resource Development and Psychology, Faculty of Social Sciences and Humanities, Universiti \\ Teknologi Malaysia, 81310 UTM Johor Bahru, Johor, Malaysia
}

\begin{abstract}
Low-income employees are among the focus individuals whose socioeconomic status plays a major role in determining positive or negative mental health status. Mental health among low-income employees is a global issue that requires a comprehensive understanding of its determinant. The objective of this study is to systematically review scientific evidence on the impact of socioeconomic status on mental health among low-income employees. This systematic review was conducted in accordance with the PRISMA guidelines, and data retrieval was done on 7th October 2020 using Scopus, Web of Science and Google Scholar. Based on the inclusion and exclusion criteria of this study, a total of 19 studies were included. Results indicate that the majority of the included studies revealed that socioeconomic status influences mental health, while two studies showed no influence. In conclusion, the findings from the review can provide guidelines to promote better mental health among low-income employees.
\end{abstract}

ARTICLE INFO

Article history:

Received: 13 April 2021

Accepted: 22 June 2021

Published: 21 September 2021

DOI: https://doi.org/10.47836/pjssh.29.3.20

E-mail addresses:

errnanadhirah@graduate.utm.my (Errna Nadhirah Kamalulil)

saisyah@utm.my (Siti Aisyah Panatik)

*Corresponding author
Keywords: Low-income employees, mental health, PRISMA, socioeconomic status, systematic review

\section{INTRODUCTION}

Poverty is a global issue that has influenced the world economic system. Socioeconomic status is one of the contributing factors of economic trends where there are disparities 
in income distribution (Hiilamo, 2014; Van Deurzen et al., 2015). Cingano (2014) reported an increase in total income inequality due to the rising of top income earners' shares and the decline of bottom incomes during the booming economics and fell during economic crises. Even for the past decade, Ferreira and Ravallion (2008) also claimed that the world was facing an income inequality crisis, particularly in developing countries; and the association between the average levels of inequality and development levels were was negative. For example, the United States, one developed country, has 38.1 million people living in poverty (11.8\%), and approximately $5.3 \%$ of individuals had family income below $50 \%$ of the poverty threshold (Semega et al., 2020). Perhaps, more surprisingly, the unemployment rate increased $5.6 \%$ in 2020 because the world economy is largely affected by the global pandemic, which leads to financial strain (Organisation for Economic Co-operation and Development, 2020).

The disparities of income distribution within a population have affected the mental health of individuals. Positive mental health is associated with high socioeconomic status, low-income inequality and low financial strain. Population-based studies from Australia (Isaacs et al., 2018), United States (Pabayo et al., 2014), Finland, Poland and Spain (Domènech-Abella et al., 2018) demonstrate that higher socioeconomic status reduces the risk of mental health issues among employees in high-income countries. Moreover, a two-year longitudinal study of 34,653 working adults (Pabayo et al., 2014) showed that rates of depression were significantly higher for bottom income earners. Dijkstra-Kersten et al. (2015) found that the more financial strain encountered among the employees, the higher the odds of being depressed. However, AdjayeGbewonyo et al. (2016) and Damaske et al. (2016) argued that the relationship between socioeconomic status and mental health is not linear. If the employees earn a higher income, then their income could cause psychological distress.

Following these considerations, the empirical evidence demonstrates the vital role of employees' mental health status as their socioeconomic status largely determined it. However, a previous study conducting on a small number of employees in a wide area, such as Damaske et al. (2016), leads to less clarification of the findings. Furthermore, due to the underrepresentation of the sample, the findings cannot be generalised to the target population resulting in weak inferences development. In addition, the relative uncertainty of the socioeconomic status definition and wide range of concepts in the mental health context cause difficulties in concluding. Accordingly, synthesising the included studies is needed to draw the empirical evidence and promote an understanding of the findings obtained regarding the impact of socioeconomic status on mental health among low-income employees across nations. 


\section{METHODOLOGY}

\section{The Publication Standard - PRISMA}

The study selection was conducted according to Preferred Reporting Items for Systematic Reviews and Meta-Analysis (PRISMA), as shown in Figure 1. PRISMA or publication standard guides the authors to describe the review process of selected articles and assists both reviewers and readers in the logical stages of searching the relevant research articles (Vu-Ngoc et al., 2018). The authors began the systematic literature review based on the publication standard by formulating a suitable research question. Next, the relevant journal databases to be used are finalised. Lastly, the authors describe the systematic searching strategy comprising three major processes (i.e., identification, screening and eligibility) in selecting of relevant research articles.

\section{Formulation of Research Question}

For this systematic review, PICo was used as guideline to formulate the research question. PICo is a method to assist the authors in formulating the suitable research question. The major components of PICo include population, phenomenon of interest and context (Stern et al., 2014). Based on these three components, the authors have followed the guideline for the review namely low-income employees (Population), the influence of socioeconomic status on mental health (Interest) and worldwide (Context) which then direct the authors to develop the main research question - Does socioeconomic status influence mental health among low-income group across nations?

\section{Resources}

Scopus, Web of Science and Google Scholar are the three online databases that have been utilized for literature search and data retrieval. Both Scopus and Web of Science are regarded among the most significant databases for social science field. In terms of journal coverage, Scopus is wider compared to Web of Science (Mongeon \& Paul-Hus, 2016) but Web of Science produces greater number of articles with high impact factors (Chadegani et al., 2013). The utilization of Google Scholar apart from these two databases in searching the relevant articles is because of the high accessibility rate of articles.

\section{Systematic Searching Strategies}

Identification, screening and eligibility are the three main processes in the systematic searching strategies (refer to Figure 1).

Identification. Identification is a method for searching for any synonym, words associated and variations in the primary keywords of the study namely socioeconomic status, mental health and low-income employees. As proposed by Okoli (2015), the keywords development is on the basis of the concise research question and the keywords are constructed by keywords suggested by Scopus, keywords used by previous studies and expert opinions. Search strings were developed by using Boolean operator, phrase searching, truncation and wildcard. 


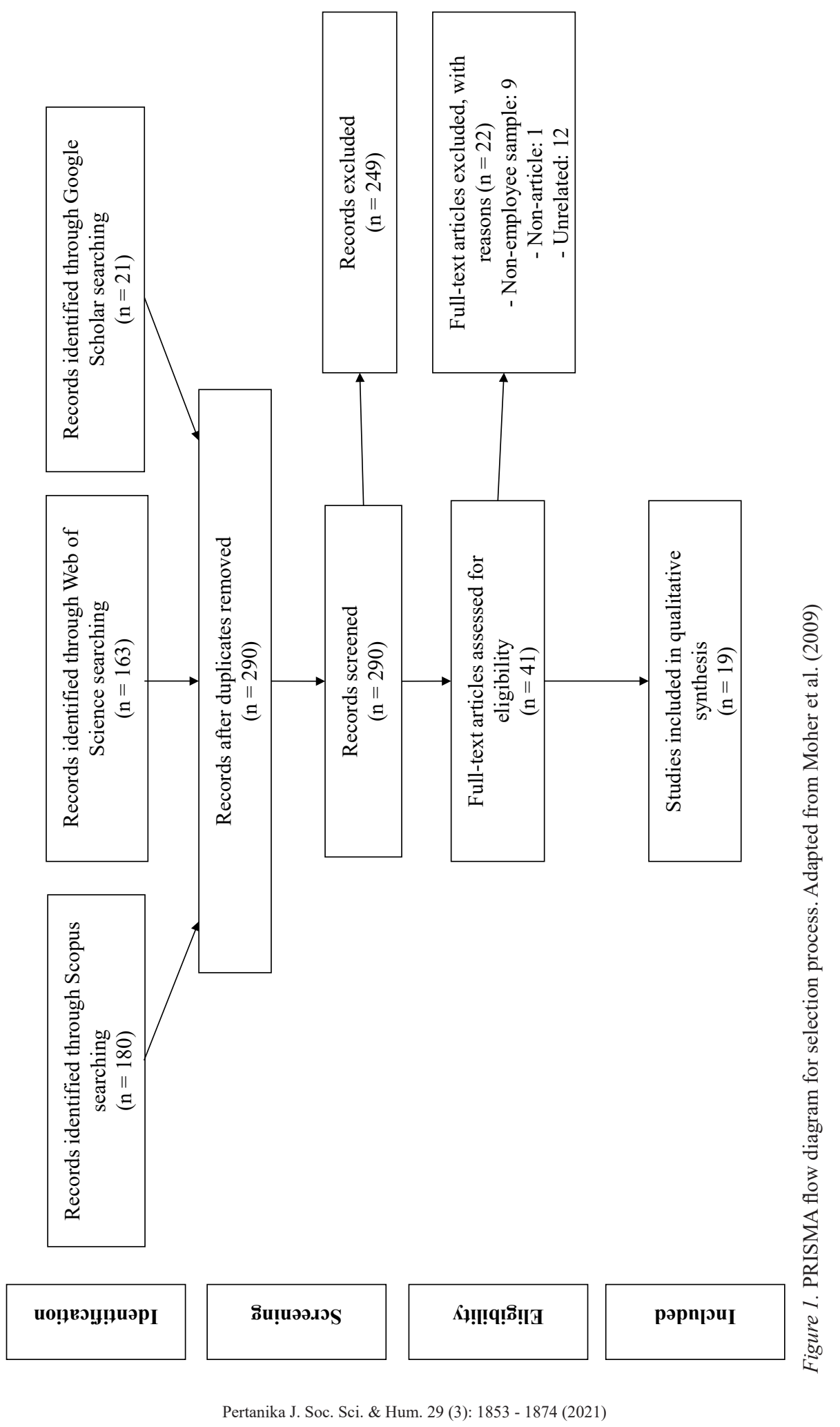


This process aims to provide the selected database with more options to browse for more relevant articles and the authors are able to widen the related keywords in the full search string on the two main databases used namely Scopus and Web of Science as shown in Table 1. For supplementary articles, Google Scholar was chosen as an additional online database as in congruence with the suggestion by Haddaway et al. (2015), Google Scholar has the ability to perform as supporting database in systematic review process and also has a high number of scholarly items that can be retrieved. These three online databases yielded a total of 364 articles.

Table 1

Query string used

\begin{tabular}{|c|c|c|}
\hline Database & Query string & Hits \\
\hline Scopus & $\begin{array}{l}\text { TITLE-ABS-KEY (( "Socio*economic status" OR } \\
\text { "Socio*economic" OR "Income" OR "Low*income" OR } \\
\text { "Income inequality" OR "Financial strain" OR "Social status" } \\
\text { OR "Social class" OR "Poverty" OR "Economic") AND } \\
\text { ("Mental health" OR "Mental illness" OR "Mental disorder*” } \\
\text { OR "Depression" OR "Depressive" OR "Health") AND } \\
\text { ("Low*income" OR "Poor" OR "B40" OR "Low*earning*” OR } \\
\text { "Low*paid" OR "employee*") ) }\end{array}$ & 180 \\
\hline $\begin{array}{l}\text { Web of } \\
\text { Science }\end{array}$ & 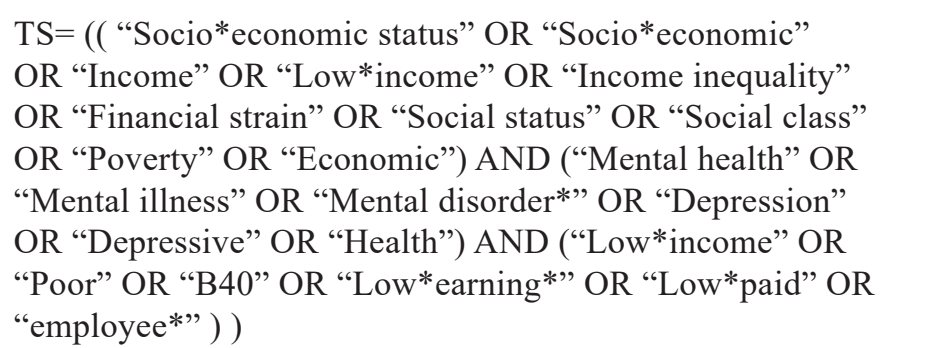 & 163 \\
\hline
\end{tabular}

Screening. The 364 articles that have been identified from the first process were then being screened. The screening process is started by importing all records into EndNote X9 reference management software package. Next, the authors used the Find Duplicates function to discard the duplicate records $(n=74)$, thus decreasing the search results to a total of 290 articles. Then, the screening process is continued with inclusion and exclusion criteria selection which is generated automatically based on the sorting feature available in the database. The search string was generated on 7 th October 2020 and in order to retrieve the most recent published articles relevant to socioeconomic status and mental health among low-income employees, the year of publications between 2010 and 2019 was chosen as the inclusion criteria. The search limitation to year 2019 was due to the searching process that started on October 
2020 and there is probability of upcoming articles to be indexed or published. Besides, the source type and document type were limited to journal and article only because empirical studies could ensure the review quality. Furthermore, the authors also limited the search to only English language articles to avoid uncertainty in understanding. After selecting the inclusion criteria with the removal of 249 articles, the records left a total of 41 articles. These 41 articles were exported to an Excel sheet (csv) in order for the eligibility process.

Eligibility. Eligibility is the second process of screening which has been carried out manually by the authors to ensure the remaining articles is appropriate and satisfied the inclusion criteria. The authors screened 41 articles by reading the titles and abstracts and identified 19 articles as relevant with the research question. Qualitative synthesis is used in this study to evaluate the data. The exclusion of 22 articles was due to non-employee samples, review article and unrelated studies. Overall, only 19 articles were included in the systematic review and the relevant data for all the included articles were extracted for further analysis.

\section{FINDINGS}

\section{Descriptive Analysis}

Figure 2 indicates the development of relevant articles published worldwide since 2010 until 2019 with a cumulative number of 19 articles. Based on the selected timeline, Fortin (2010) was the first scholar who published the related article. The peak of publications among the scholars was in $2014(n=5)$ while 2013 and 2019 have zero record. Evidently, the growing of related publications is inconsistent from year 2010 to 2019 .

Table 2 displays the socioeconomic status measures from the prior research. Almost third-quarter of the studies (73.68\%) measured socioeconomic status by using household income and more than halves of the studies $(57.89 \%)$ used educational level as one of the important determinants of socioeconomic status. Occupation and financial strain determinants were used thrice (15.79\%) and twice (10.53\%) of the studies respectively. Economic inactivity, household debt, household size, housing type, income below 100\% Federal Poverty and personal income were the least determinants used to assess socioeconomic status with only one study each (5.26\%).

Table 3 presents the list of instruments used to measure mental health. The authors found 15 different instruments utilized, of which the self-assessed health status was the most frequent with four times used $(21.05 \%)$, followed by three times (15.79\%) used of Composite International Diagnostic Interview (CIDI 3.0) and General Health Questionnaire (GHQ-12). Kessler Psychological Distress Scale was used twice $(10.53 \%)$ with 10 items while once $(5.26 \%)$ with only six items. The other listed instruments were utilized once $(5.26 \%)$ by scholars in their studies. Overall, the majority of instruments assess mental health on the basis of depression, anxiety and stress. 


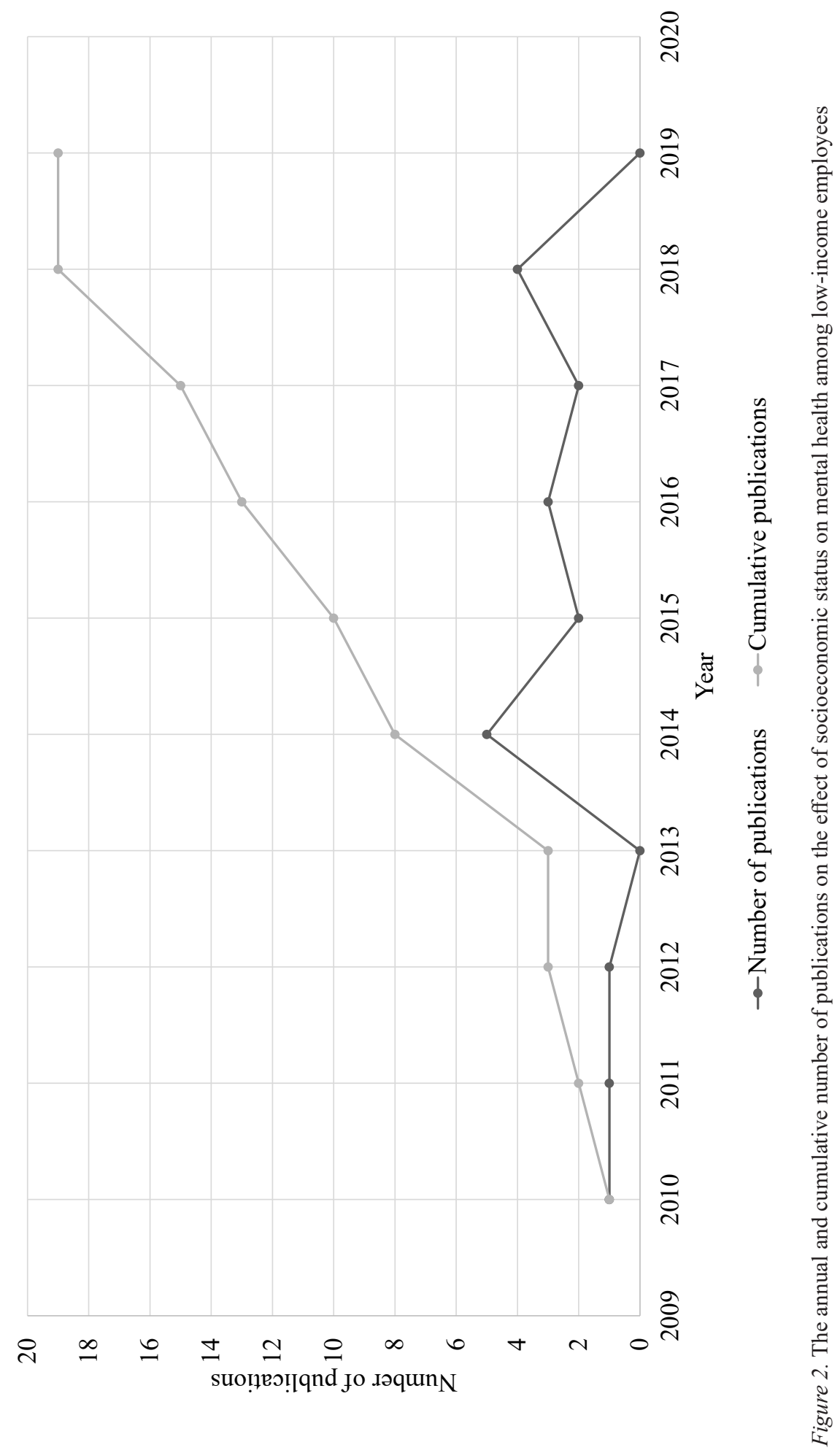

Pertanika J. Soc. Sci. \& Hum. 29 (3): 1853 - 1874 (2021) 
Table 2

Socioeconomic status measures $(n=19)$

\begin{tabular}{lcc}
\hline Measures & $N$ of studies & $\%$ \\
\hline Household income & 14 & 73.68 \\
Educational level & 11 & 57.89 \\
Occupation & 3 & 15.79 \\
Financial strain & 2 & 10.53 \\
Economic inactivity & 1 & 5.26 \\
Household debt & 1 & 5.26 \\
Household size & 1 & 5.26 \\
Housing type & 1 & 5.26 \\
Income below 100\% Federal Poverty Level & 1 & 5.26 \\
Personal income & 1 & 5.26 \\
\hline
\end{tabular}

Table 3

List of instruments used to assess mental health $(n=19)$

\begin{tabular}{lcc}
\hline Instruments & $N$ of studies & $\%$ \\
\hline Self-assessed health status & 4 & 21.05 \\
Composite International Diagnostic Interview (CIDI & 3 & 15.79 \\
3.0) & 3 & 15.79 \\
General Health Questionnaire (GHQ-12) & 2 & 10.53 \\
Center for Epidemiologic Studies Depression (CESD) & & \\
scale & 2 & 10.53 \\
Kessler Psychological Distress Scale (K10) & 2 & 10.53 \\
Perceived Stress Scale (PSS) & 1 & 5.26 \\
Alcohol Use Disorder and Associated Disabilities & & \\
Interview Schedule-5 (AUDADIS-5) & 1 & 5.26 \\
Generalized-anxiety disorder-7 (GAD-7) & 1 & 5.26 \\
Geriatric Depression Scale-15 (GDS- 15) & 1 & 5.26 \\
Health-Related Quality of Life (HRQoL) & 1 & 5.26 \\
Hopkins Symptom Check List (HSCL) & 1 & 5.26 \\
Kessler Psychological Distress Scale (K6) & 1 & 5.26 \\
Patient Health Questionnaire-9 (PHQ-9) & 1 & 5.26 \\
Symptom Checklist-90-Revised (SCL-90-R) & 1 & 5.26 \\
World Health Organization Quality of Life Instrument- & & \\
Older Adults Module (WHOQOL-OLD) &
\end{tabular}




\section{Socioeconomic Status and Mental Health}

The research included 15 cross-sectional studies $(78.95 \%)$ and four longitudinal studies (21.05\%; refer Table 4). The participants of the relevant studies were among employees who are currently working in an organization. The total participation of employees in the 19 studies was 1,755,021 ranging from the minimum of 116 participants (Test et al., 2014) to the maximum of 1,578,189 participants (Kim et al., 2017).

The study on the impact of socioeconomic status toward mental health has been carried out in multiple countries representing first, second and third world countries, namely Canada, Malaysia and Cambodia, but most of the studies were conducted in United States (Asebedo \& Wilmarth, 2017; Damaske et al., 2016; Hoffman \& Wallace, 2018; Pabayo et al., 2014; Wickrama et al., 2012). Three studies investigated socioeconomic status and other determinants namely trauma, social support and unhealthy behavior with mental health (Jarl et al., 2015; Lazzarino et al., 2014; Ng et al., 2014) while a study by Damaske et al. (2016) assessed the effect of socioeconomic status on mental health and other employees' outcomes namely momentary workplace perceptions. Two of the 19 studies integrated multiple predictor variables including socioeconomic status, caregiver status and weak labor force attachment and outcome variables consisting mental health, unhealthy behavior and prevalence of illness (Fortin, 2010; Hoffman \& Wallace, 2018).
The other 13 studies in this systematic review exclusively investigated the effect of socioeconomic status on mental health.

Two out of 19 studies reported that socioeconomic status positively correlated with mental health while 17 studies showed a negative correlation between socioeconomic status and mental health. The demographic variables also showed that age, population group (African), marital status (single) and gender (female) were independently correlated with greater depressive symptoms. Adjaye-Gbewonyo et al. (2016) exclusively analyzed the influence of level of socioeconomic status on mental health status. The data analysis of this longitudinal study recommended that changes in district income inequality will produce significant changes in socioeconomic status and mental health status. However, the findings showed that there was no association between district income inequality and mental health status and thus, the changes in mental health status cannot be predicted by the changes in district income inequality. In line with the findings from Damaske et al. (2016), a higher income was associated with lower odds of happiness at workplace, greater stress and perceived stress representing only one out of six studies carried out in United States that shows positive correlation between these two variables.

For the other five studies conducted in United States, the results showed negative correlation between socioeconomic status and mental health. Two longitudinal studies' findings show that depression was affected by low levels of education and household 
Errna Nadhirah Kamalulil and Siti Aisyah Panatik

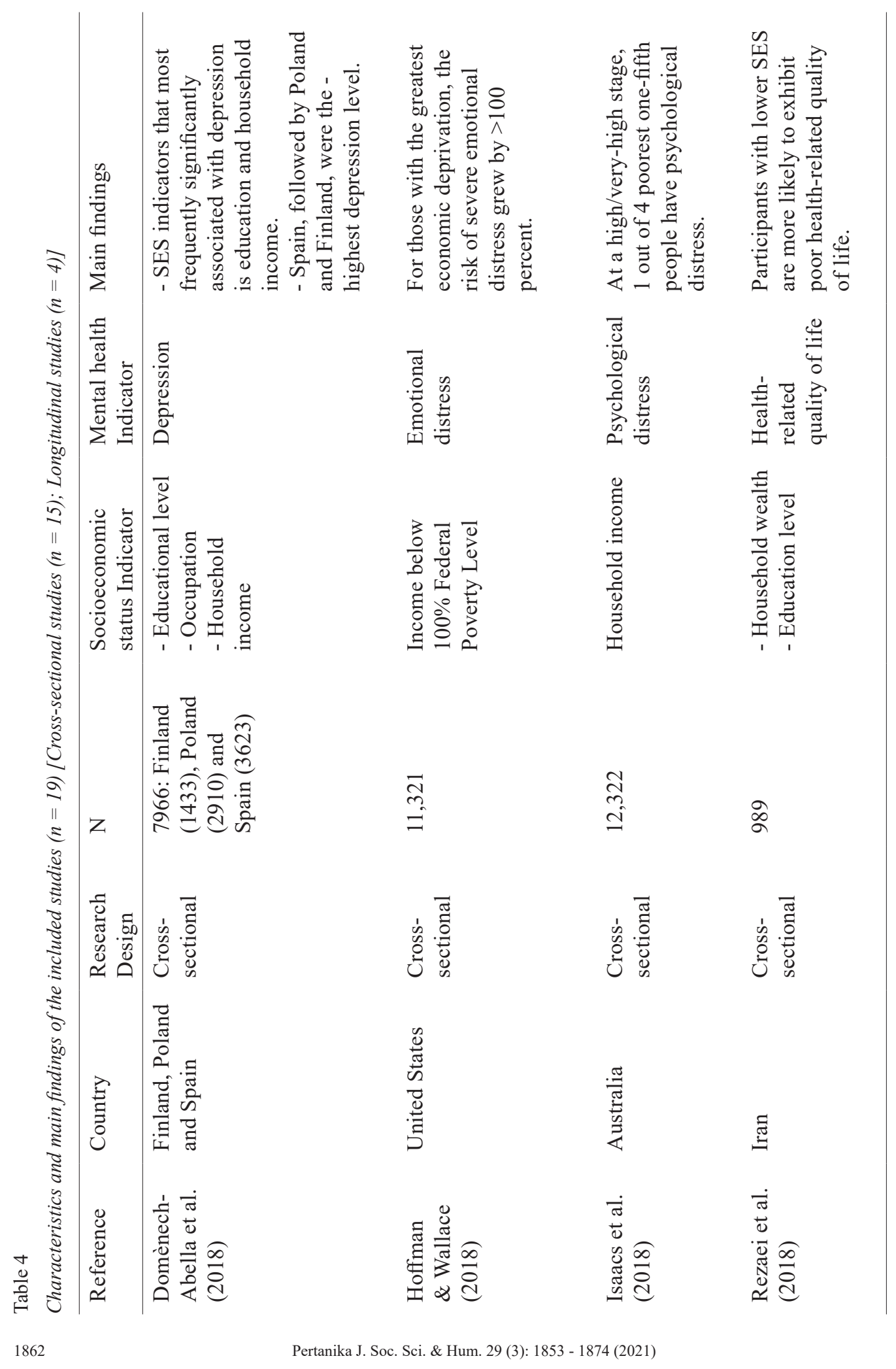


Socioeconomic Status and Mental Health: A Systematic Literature Review

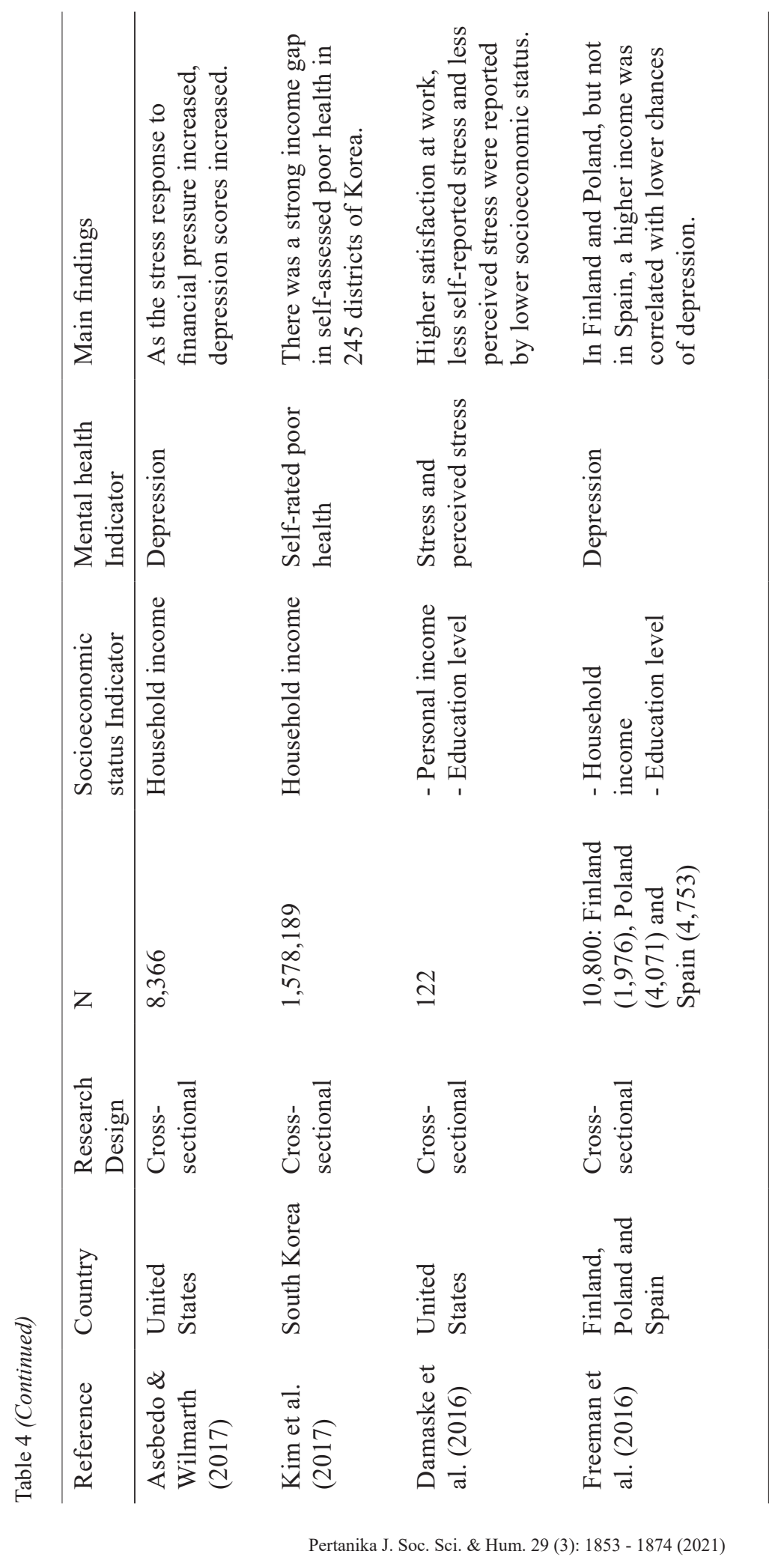


Errna Nadhirah Kamalulil and Siti Aisyah Panatik

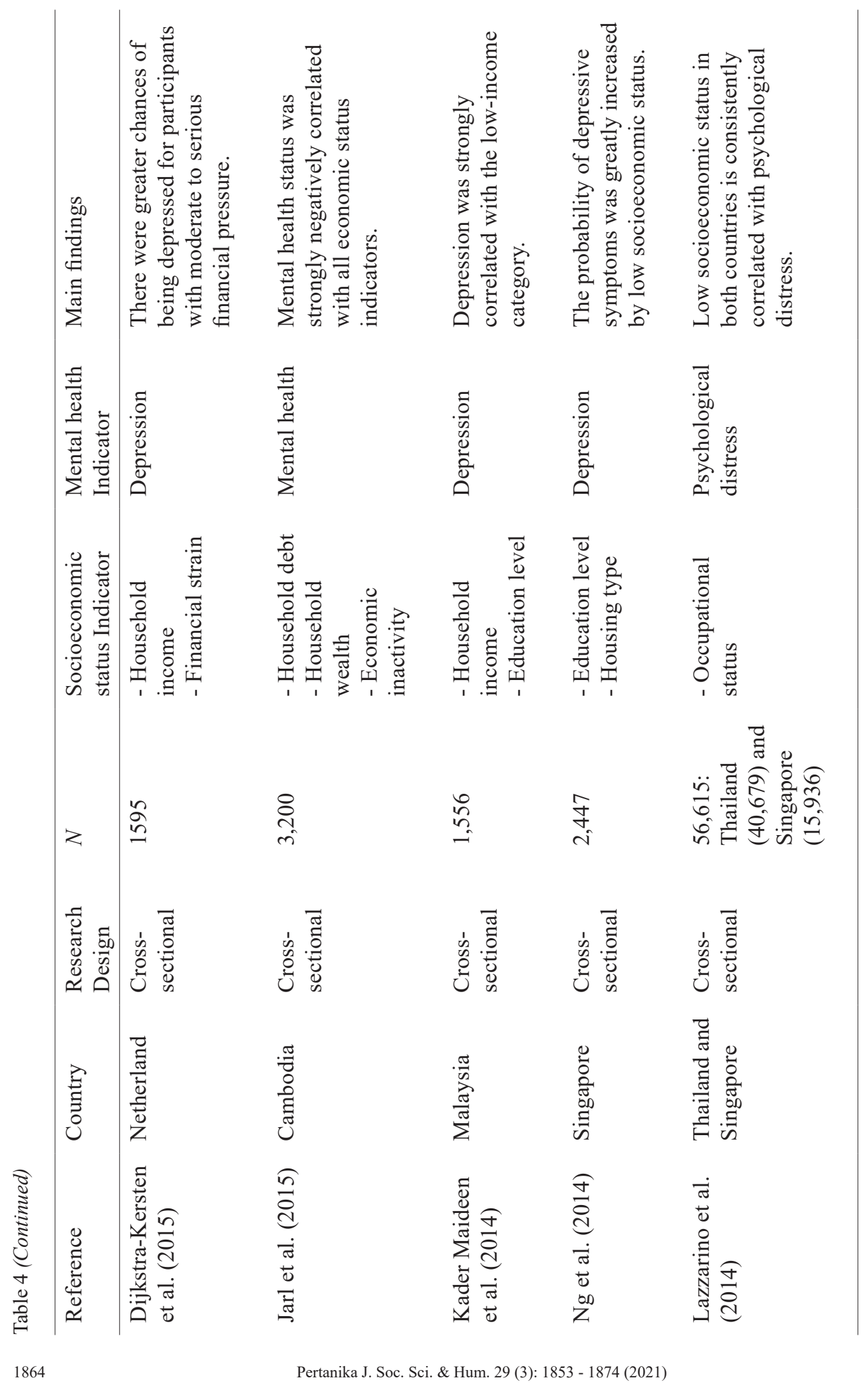


Socioeconomic Status and Mental Health: A Systematic Literature Review

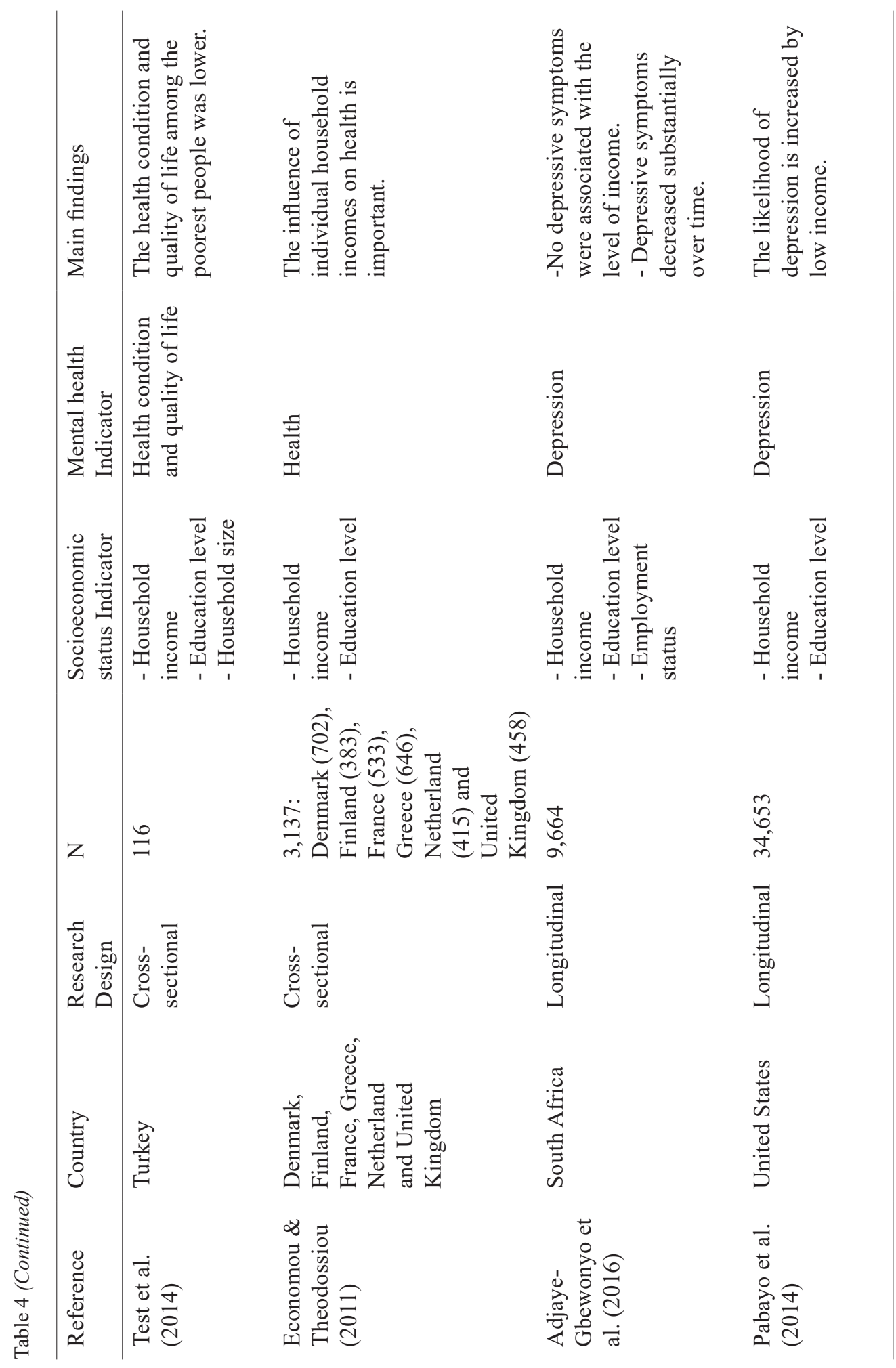

Pertanika J. Soc. Sci. \& Hum. 29 (3): 1853 - 1874 (2021) 
Errna Nadhirah Kamalulil and Siti Aisyah Panatik

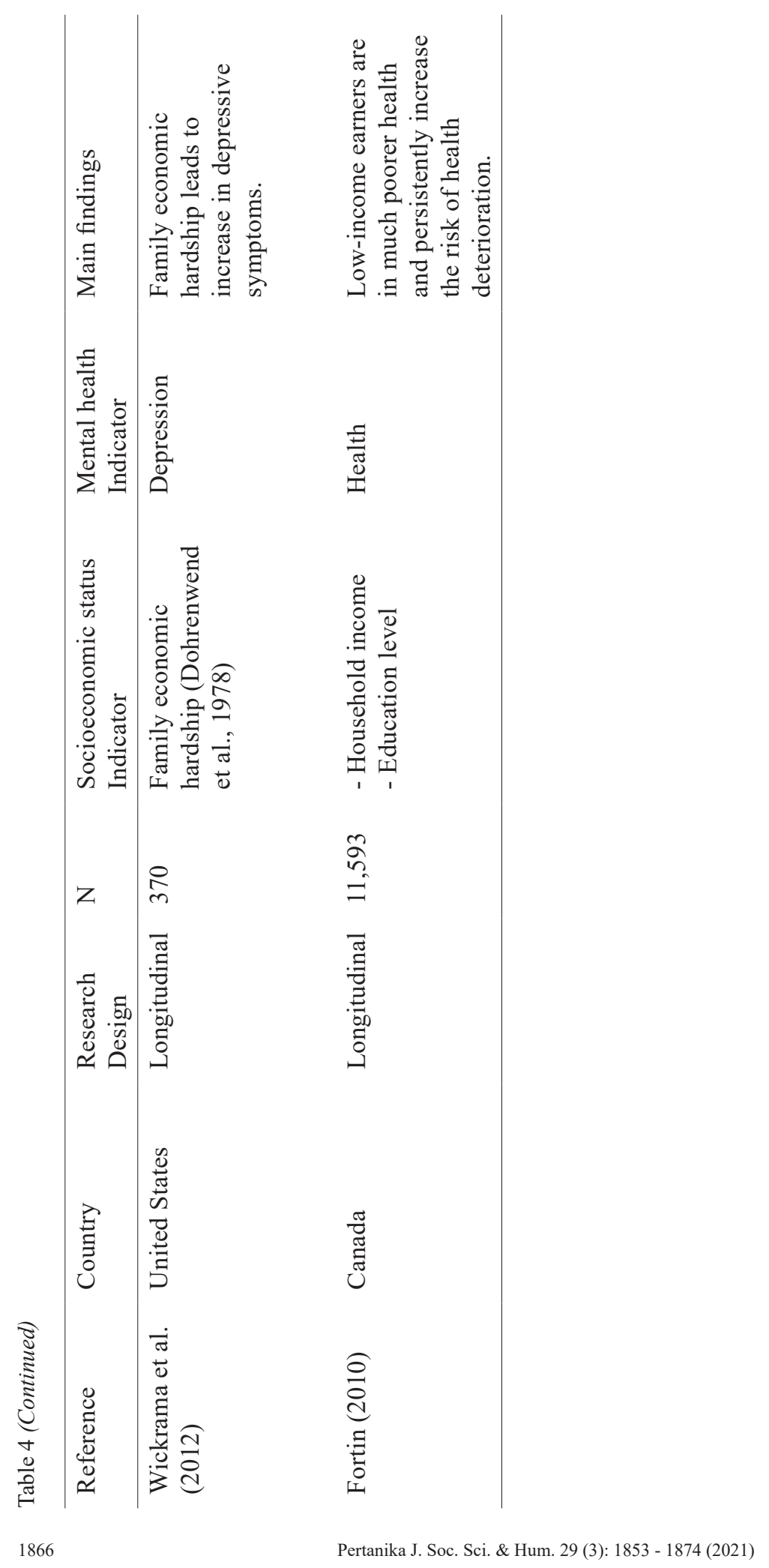


income (Pabayo et al., 2014) and high level of family economic hardship (Wickrama et al., 2012). These results also supported by a cross-sectional study from Asebedo and Wilmarth (2017) that higher score of depression was associated with greater response rate on financial strain. Moreover, another study investigated whether the effects of socioeconomic status were moderated by caregiver status. The data analysis revealed that this interaction was not significant (Hoffman \& Wallace, 2018).

A study by Freeman et al. (2016) in three different countries namely Finland, Poland and Spain, found a significant impact of socioeconomic status measures including household income and educational level on depression in Finland and Poland, but not in Spain. However, the latest study conducted in the same European countries demonstrated that lower income was associated with higher probabilities of having depression in Finland, Poland and Spain (DomènechAbella et al., 2018). This study included additional variables of mediators namely behavioral, psychosocial and material factors which psychosocial factors and especially loneliness had the strongest correlations with depression while material factors and financial strain, in particular revealed as the highest mediating function in the relationship between socioeconomic status and depression.

In addition, five studies conducted in Asian countries revealed a significant effect of socioeconomic status on mental health. Studies discovered that among the low-income group, mental health status in
Cambodia was strongly positively correlated with all economic status determinants including household debt and economic inactivity (Jarl et al., 2015) and depression in Malaysia had a strong correlation with economic status namely household income and education level (Kader Maideen et al., 2014). Singapore has carried out two relevant studies (Lazzarino et al., 2014; $\mathrm{Ng}$ et al., 2014) but one of it was collaborated with Thailand by Lazzarino et al. (2014) with larger study samples. Both of these studies established that socioeconomic status was strongly and negatively correlated with psychological distress with additional findings revealed inconsistent moderation of social support across socioeconomic status groups (Ng et al., 2014) and unhealthy behavior was inconsistently associated to psychological distress (Lazzarino et al., 2014). Among all of the included studies, the largest number of samples included in the study was $1,578,189$ in South Korea which also reported socioeconomic status was negatively associated with mental health status (Kim et al., 2017).

Furthermore, improving economic stability was linked to reduction of emotional distress among low-income employees (Isaacs et al., 2018). This result is similar from those reported in previous longitudinal included studies where lower economic determinants and weak labour force attachment led to mental health issue and an increase of illness prevalence (Fortin, 2010). Socioeconomic status also had a direct negative effect on depression and anxiety Dijkstra-Kersten et al. (2015), 
emotional health in general (Economou \& Theodossiou, 2011) and health-related quality of life (Rezaei et al., 2018; Test et al., 2014).

In summary, the different findings obtained from the 19 included studies were contributed from different demographic features, sample sizes and national cultures. Besides, various determinants of socioeconomic status and mental health scales utilized in the studies could also contribute to various research outcomes. Therefore, in-depth studies in the future by various scholars are required to acquire heterogenous research findings.

\section{DISCUSSION}

The main aim of this study is to carry out a systematic review of the empirical studies on the impact of socioeconomic status on mental health among low-income employees. Most of the prior research indicated that socioeconomic status affects mental health among the low-income employees. The longitudinal study also proved that the socioeconomic status influence mental health over time. Primarily, it is vital to emphasize that socioeconomic status has been assessed through various measures. Several studies only used household income as the determinant (Asebedo \& Wilmarth, 2017; Isaacs et al., 2018; Kim et al., 2017) while other studies integrated other related measures such as employment status, education level, housing type, household debt and household size (Adjaye-Gbewonyo et al., 2016; Freeman et al., 2016; Jarl et al., 2015; Test et al., 2014). A study from
Lazzarino et al. (2014) exclusively utilized occupational status as socioeconomic status measures. The inconsistencies of conceptual and operational definitions of the concept used in the empirical studies lead to difficulties in appropriately defining the variable. Huang et al. (2017) and Präg et al. (2016) highly recommend the integration of both objective and subjective measures of socioeconomic status to ensure the clarity in the concept of socioeconomic status in the aspects of individual and social or economic. Objective socioeconomic status is regarded as the position of one's economic and social standing in comparison to others, as determined by three measures including household income, education level and occupational status which have widely used by various scholars (AdjayeGbewonyo et al., 2016; Domènech-Abella et al., 2018) while subjective socioeconomic status is an individual's perception of his or her own status in relation to others (Goodman et al., 2001). The subjective socioeconomic status was found to be significantly related to the three measures of objective socioeconomic status (Ostrove et al., 2000) which implies that both subjective and objective socioeconomic status may complement each other in influencing its psychological effects. Thus, clarifications on the variables according to specific research discipline particularly in developing phase is important by understanding the concepts and outcomes of recent studies.

Improving the low-income employees' socioeconomic status can be an important source of positive mental health. As 
established by the reviewed studies, employees who have higher socioeconomic status are tend to portray greater positive affect, feel less depressed and have better levels of emotional status compared to lower-income employees. The significant measure of mental health was depression (Domènech-Abella et al., 2018; Kader Maideen et al., 2014; Wickrama et al., 2012) and as acknowledged by other studies (Damaske et al., 2016; Dikshit \& Acharya, 2017; Economou \& Theodossiou, 2011; Lazzarino et al., 2014), emotional health, stress, anxiety and psychological distress have also been indicated as strong measures of mental health. Nevertheless, the better outcome of employees' mental health is affected by the multidimensional concept of socioeconomic status that is based on objective and subjective socioeconomic status. Evidently, Bøe et al. (2019) and Honjo et al. (2014) presented both objective and subjective socioeconomic status to be among the prime contributors of mental health among low-income employees in order to ensure the comprehensiveness of the employees' socioeconomic status through their privilege, resources, power and control.

For the association between socioeconomic status and mental health among low-income employees based on developed, developing and underdeveloped countries as used by United Nations Development Programme (UNDP), there are different outcomes in several studies. This review comprised of studies from 11 developed countries, seven developing countries and only one underdeveloped country. All studies found that socioeconomic status among low-income employees in developed and developing countries was negatively associated with mental health. By contrast, Adjaye-Gbewonyo et al. (2016) found that in South Africa as developing nation, there was no association between socioeconomic status and mental health over time and Damaske et al. (2016) reported positive association between socioeconomic status and mental health among lowincome employees in United States as the developed country. In underdeveloped country, studies examining the association between socioeconomic status and mental health are scarce (Jarl et al., 2015) even though underdeveloped country is among the nations with the lowest Gross National Income (GNI) per capita (World Bank, 2021). Therefore, these evidences linking socioeconomic status to mental health outcomes inconsistently address a number of key issues that could improve in causal inference, including the overall economic indicators. For that reason, the examination on this potential nature of this association based on GNI per capita from lowest to highest-income countries is required.

\section{Strengths and Limitations of Review}

This systematic review is the first to synthesize included studies on the impact of socioeconomic status on mental health among low-income employees because the other relevant reviews were conducted among children, adolescents and general population in low, middle and high-income 
countries (Lund et al., 2010; Patel et al., 2018; Reiss et al., 2019). Besides, multiple databases were utilized including Scopus and Web of Science as among the highest impact factors journal for psychology research discipline while Google Scholar as an additional academic source. Furthermore, the literature shows that income stability affects different states of mental health namely depression, anxiety and stress and mental health outcomes in this review is mostly researched in specific constructs. Hence, this review demonstrates the significance of recent research calls for both individual and organizational approaches for income equalities and an increased emphasis on low-income employees' positive mental health.

Out of 19 studies, majority of the studies were cross-sectional leading to inability of identifying the trends in the characteristics of low-income employees. For this reason, longitudinal study is a powerful research design that are recommended in the future studies to determine to what extent socioeconomic status influences mental health of employees over a period of time. Next, several studies were carried out in unknown organizational settings that could be the factors of the inconsistencies of research findings. Therefore, the authors suggest for future studies to conduct research that focuses on specific organizational settings.

\section{Implications for Practice}

This review offers constructive resources for efforts to establish a stable and equal income distribution that promote lowpaid employees' positive mental health. Examining the influence of socioeconomic status on mental health and other individual outcomes will assist health care professionals and psychologists to understand how income stability improves low-income employees' emotional health. As supported by Golberstein (2016), the increasing number of studies on the mental health outcomes that due to the stability and security of income will help the patients' diagnosis and treatment. Apart from assisting the health care professionals, understanding the impact of socioeconomic status on mental health status could help government not just for policy amendment or making through the critical issues identification, but also to encourage the comprehensiveness towards equitable society. In addition, these findings could be the fundamental idea for future research on discovering this issue by integrating both objective and subjective economic measures and defining mental health in more extensive.

\section{CONCLUSION}

Based on this review, the findings provide evidence of the significance of employees' socioeconomic status to achieve positive mental health status. Examining the impact of socioeconomic status and understanding the association between socioeconomic status and mental health are beneficial for mental health state improvement which eventually promote a positive overall health among low-income employees. This review will assist the government in formulating 
effective strategies for an equal income distribution and this is one of the ways for the poverty reduction. Besides, this review also acts as direction for health professionals and psychologists to treat the patients' emotional effects with suitable approaches while further studies that examine the influence of economic status on employees' emotional health through longitudinal and qualitative studies are highly required among scholars. Hence, the integration of government, clinical and research efforts will lead to positive thoughts, behaviors and emotions which eventually promoting productive and effective employees at the workplace.

\section{ACKNOWLEDGMENT}

Funder by the Ministry of Higher Education under FRGS, Registration Proposal No: R.J130000.7853.5F172

\section{REFERENCES}

Adjaye-Gbewonyo, K., Avendano, M., Subramanian, S. V., \& Kawachi, I. (2016). Income inequality and depressive symptoms in South Africa: A longitudinal analysis of the National Income Dynamics Study. Health Place, 42, 37-46. https:// doi.org/10.1016/j.healthplace.2016.08.013

Asebedo, S. D., \& Wilmarth, M. J. (2017). Does how we feel about financial strain matter for mental health? Journal of Financial Therapy, 8(1), 62-80. https://doi.org/10.4148/1944-9771.1130

Bøe, T., Petrie, K. J., Sivertsen, B., \& Hysing, M. (2019). Interplay of subjective and objective economic well-being on the mental health of Norwegian adolescents. SSM - Population Health, 9, 1-8. https://doi.org/10.1016/j. ssmph.2019.100471
Chadegani, A., Salehi, H., Md Yunus, M. M., Farhadi, H., Fooladi, M., Farhadi, M., \& Ale Ebrahim, N. (2013). A comparison between two main academic literature collections: Web of science and scopus databases. Asian Social Science, 9(5), 18-26. https://doi.org/10.5539/ass.v9n5p18

Cingano, F. (2014). Trends in income inequality and its impact on economic growth. In OECD Social, Employment, and Migration Working Papers (No. 163). https://doi.org/10.1787/5jxrjncwxv6jen

Damaske, S., Zawadzki, M. J., \& Smyth, J. M. (2016). Stress at work: Differential experiences of high versus low SES workers. Social Science \& Medicine, 156, 125-133. https://doi. org/10.1016/j.socscimed.2016.03.010

Dijkstra-Kersten, S. M. A., Biesheuvel-Leliefeld, K. E. M., van der Wouden, J. C., Penninx, B. W. J. H., \& van Marwijk, H. W. J. (2015). Associations of financial strain and income with depressive and anxiety disorders. Journal of Epidemiology and Community Health, 69(7), 660-665. https:// doi.org/10.1136/jech-2014-205088

Dikshit, S., \& Acharya, S. K. (2017). Impact of occupational stress on the work life balance of teaching professionals in higher education with special reference to Bhubaneswar City, Odisha. Advances in Economics and Business Management, 4(6), 357-361.

Dohrenwend, B. S., Krasnoff, L., Askenasy, A. R., \& Dohrenwend, B. P. (1978). Exemplification of a method for scaling life events: The PERI Life Events Scale. Journal of Health and Social Behavior, 19(2), 205-229. https://doi. org/10.2307/2136536

Domènech-Abella, J., Mundó, J., Leonardi, M., Chatterji, S., Tobiasz-Adamczyk, B., Koskinen, S., Ayuso-Mateos, J. L., \& Haro, J. M. (2018). The association between socioeconomic status and depression among older adults in Finland, 
Poland and Spain: A comparative cross-sectional study of distinct measures and pathways. Journal of Affective Disorders, 241, 311-318. https://doi. org/10.1016/j.jad.2018.08.077

Economou, A., \& Theodossiou, I. (2011). Poor and sick: Estimating the relationship between household income and health. Review of Income and Wealth, 57(3), 395-411. https://doi. org/10.1111/j.1475-4991.2010.00416.x

Ferreira, F. H. G., \& Ravallion, M. (2008). Global poverty and onequality: A review of the evidence. The World Bank. https://doi.org/10.1016/j. contraception.2014.01.015

Fortin, M. (2010). The connection between low income, weak labour force attachment and poor health. Canadian Studies in Population, 37, 2552. https://doi.org/10.25336/p62s5f

Freeman, A., Tyrovolas, S., Koyanagi, A., Chatterji, S., Leonardi, M., Ayuso-Mateos, J. L., TobiaszAdamczyk, B., Koskinen, S., Rummel-Kluge, C., \& Haro, J. M. (2016). The role of socioeconomic status in depression: Results from the COURAGE (aging survey in Europe). BMC Public Health, 16(1), 1-8. https://doi. org/10.1186/s12889-016-3638-0

Golberstein, E. (2016). The effects of income on mental health: Evidence from the Social Security Notch. Physiology \& Behavior, 176(1), 139-148.

Goodman, E., Adler, N. E., Kawachi, I., Frazier, A. L., Huang, B., \& Colditz, G. A. (2001). Adolescents' perceptions of social status: Development and evaluation of a new indicator. Pediatrics, 108(2), 1-8. https://doi.org/10.1542/peds.108.2.e31

Haddaway, N. R., Collins, A. M., Coughlin, D., \& Kirk, S. (2015). The role of Google scholar in evidence reviews and its applicability to grey literature searching. PLoS ONE, 10(9), Article e0138237. https://doi.org/10.1371/journal. pone. 0138237
Hiilamo, H. (2014). Is income inequality "toxic for mental health"? An ecological study on municipal level risk factors for depression. PLoS ONE, 9(3), Article e92775. https://doi. org/10.1371/journal.pone.0092775

Hoffman, G. J., \& Wallace, S. P. (2018). The cost of caring: Economic vulnerability, serious emotional distress, and poor health behaviors among paid and unpaid family and friend caregivers. Research on Aging, 40(8), 791-809. https://doi.org/10.1177/0164027517742430

Honjo, K., Kawakami, N., Tsuchiya, M., Sakurai, K., \& WMH-J 2002-2006 Survey Group. (2014). Association of subjective and objective socioeconomic status with subjective mental health and mental disorders among Japanese men and women. International Journal of Behavioral Medicine, 21(3), 421-429. https:// doi.org/10.1007/s12529-013-9309-y

Huang, S., Hou, J., Sun, L., Dou, D., Liu, X., \& Zhang, H. (2017). The effects of objective and subjective socioeconomic status on subjective well-being among rural-to-urban migrants in China: The moderating role of subjective social mobility. Frontiers in Psychology, 8, 819. https://doi. org/10.3389/fpsyg.2017.00819

Isaacs, A. N., Enticott, J., Meadows, G., \& Inder, B. (2018). Lower income levels in Australia are strongly associated with elevated psychological distress: Implications for healthcare and other policy areas. Frontiers in Psychiatry, 9, 1-9. https://doi.org/10.3389/fpsyt.2018.00536

Jarl, J., Cantor-Graae, E., Chak, T., Sunbaunat, K., \& Larsson, C. A. (2015). Trauma and poor mental health in relation to economic status: The case of Cambodia 35 years later. PLoS ONE, 10(8), Article e0136410. https://doi.org/10.1371/ journal.pone. 0136410

Kader Maideen, S. F., Mohd Sidik, S., Rampal, L., \& Mukhtar, F. (2014). Prevalence, associated factors and predictors of depression among 
adults in the community of Selangor, Malaysia. PLoS ONE, 9(4), Article e95395. https://doi. org/10.1371/journal.pone.0095395

Kim, I., Bahk, J., Yun, S. C., \& Khang, Y. H. (2017). Income gaps in self-rated poor health and its association with life expectancy in 245 districts of Korea. Epidemiology and Health, 39, Article e2017011. https://doi.org/10.4178/ epih.e2017011

Lazzarino, A. I., Yiengprugsawan, V., Seubsman, S. ang, Steptoe, A., \& Sleigh, A. C. (2014). The associations between unhealthy behaviours, mental stress, and low socio-economic status in an international comparison of representative samples from Thailand and England. Globalization and Health, 10(10), 1-8. https:// doi.org/10.1186/1744-8603-10-10

Lund, C., Breen, A., Flisher, A. J., Kakuma, R., Corrigall, J., Joska, J. A., Swartz, L., \& Patel, V. (2010). Poverty and common mental disorders in low and middle income countries: A systematic review. Social Science and Medicine, 71(3), 517-528. https://doi.org/10.1016/j. socscimed.2010.04.027

Moher, D., Liberati, A., Tetzlaff, J., Altman, D. G., \& Group, T. P. (2009). Preferred reporting items for systematic reviews and meta-analyses: The PRISMA statement. PLoS Medicine, 6(7), Article e1000097. https://doi.org/10.1371/journal. pmed.1000097

Mongeon, P., \& Paul-Hus, A. (2016). The journal coverage of Web of Science and Scopus: A comparative analysis. Scientometrics, 106(1), 213-228. https://doi.org/10.1007/s11192-0151765-5

Ng, C. W. L., Tan, W. S. hi., Gunapal, P. P. G., Wong, L. Y. i., \& Heng, B. H. oo. (2014). Association of socioeconomic status (SES) and social support with depressive symptoms among the elderly in Singapore. Annals of the Academy of Medicine, Singapore, 43(12), 576-587.
Okoli, C. (2015). A guide to conducting a standalone systematic literature review. Communications of the Association for Information Systems, 37(1), 879-910. https://doi.org/10.17705/1CAIS.03743

Organisation for Economic Co-operation and Development. (2020). OECD Unemployment Rates (Issue May). https://www.oecd.org/sdd/ labour-stats/unemployment-rates-oecd-05-2020. pdf

Ostrove, J. M., Adler, N. E., Kuppermann, M., \& Washington, A. E. (2000). Objective and subjective assessments of socioeconomic status and their relationship to self-rated health in an ethnically diverse sample of pregnant women. Health Psychology, 19(6), 613-618. https://doi. org/10.1037/0278-6133.19.6.613

Pabayo, R., Kawachi, I., \& Gilman, S. E. (2014). Income inequality among American states and the incidence of major depression. Journal of Epidemiology and Community Health, 68, 110115. https://doi.org/10.1136/jech-2013-203093

Patel, V., Burns, J. K., Dhingra, M., Tarver, L., Kohrt, B. A., \& Lund, C. (2018). Income inequality and depression: A systematic review and metaanalysis of the association and a scoping review of mechanisms. World Psychiatry, 17(1), 76-89. https://doi.org/10.1002/wps.20492

Präg, P., Mills, M. C., \& Wittek, R. (2016). Subjective socioeconomic status and health in crossnational comparison. Social Science and Medicine, 149, 84-92. https://doi.org/10.1016/j. socscimed.2015.11.044

Reiss, F., Meyrose, A.-K., Otto, C., Lampert, T., Klasen, F., \& Ravens-Sieberer, U. (2019). Socioeconomic status, stressful life situations and mental health problems in children and adolescents: Results of the German BELLA cohort-study. PLoS ONE, 14(3), Article e0213700. https://doi.org/10.1371/journal. pone. 0213700 
Rezaei, S., Hajizadeh, M., Khosravipour, M., Khosravi, F., \& Rezaeian, S. (2018). Socioeconomic inequalities in poor health-related quality of life in Kermanshah, Western Iran: A decomposition analysis. Journal of Research in Health Sciences, 18(1), 1-6. https://doi.org/10.26719/emhj.20.001

Semega, J., Kollar, M., Creamer, J., \& Mohanty, A. (2020). Income and poverty in the United States: 2018. In Current Population Reports. U.S. Government Printing Office. https:// www.census.gov/content/dam/Census/library/ publications/2019/demo/p60-266.pdf

Stern, C., Jordan, Z., \& McArthur, A. (2014). Developing the review question and inclusion criteria. AJN, American Journal of Nursing, 114(4), 53-56. https://doi.org/10.1097/01. NAJ.0000445689.67800.86

Test, I. S. T., Test, M. U., Status, H., \& Analizi, V. (2014). Investigating the effects of poverty on health and quality of life in poor people aged 65 and over in Etimesgut district, Ankara. Turkish Journal of Geriatrics, 17(4), 397-403.

Van Deurzen, I., Van Ingen, E., \& Van Oorschot, W. J. H. (2015). Income inequality and depression: The role of social comparisons and coping resources. European Sociological Review, 31(4), 477-489. https://doi.org/10.1093/esr/jcv007
Vu-Ngoc, H., Elawady, S. S., Mehyar, G. M., Abdelhamid, A. H., Mattar, O. M., Halhouli, O., Vuong, N. L., Mohd Ali, C. D., Hassan, U. H., Kien, N. D., Hirayama, K., \& Huy, N. T. (2018). Quality of flow diagram in systematic review and/or meta-analysis. PLoS ONE, 13(6), Article e0195955. https://doi.org/10.1371/journal. pone. 0195955

Wickrama, K. A. S., Surjadi, F. F., Lorenz, F. O., Conger, R. D., \& O’Neal, C. W. (2012). Family economic hardship and progression of poor mental health in middle-aged husbands and wives. Family Relations: Interdisciplinary Journal of Applied Family Studies, 61(2), 297-312. https://doi.org/10.1111/j.17413729.2011.00697.x

World Bank. (2021). World Bank Country and Lending Groups. https://datahelpdesk.worldbank.org/ knowledgebase/articles/906519-world-bankcountry-and-lending-groups\#: :text=For the current 2021 fiscal,those with a GNI per 